\title{
Self-management knowledge and practice of type 2 diabetes mellitus patients in Baghdad, Iraq: a qualitative study
}

This article was published in the following Dove Press journal: Diabetes, Metabolic Syndrome and Obesity:Targets and Therapy

\author{
Ehab Mudher Mikhael ${ }^{1,2}$ \\ Mohamed Azmi Hassali ${ }^{2}$ \\ Saad Abdulrahman Hussain ${ }^{3}$ \\ Nizar Shawky ${ }^{4}$ \\ 'Department of Clinical Pharmacy, \\ College of Pharmacy, University of \\ Baghdad, Baghdad, Iraq; '2Department \\ of Social and Administrative Pharmacy, \\ School of Pharmaceutical Sciences, \\ Universiti Sains Malaysia, Pulau \\ Pinang, Malaysia; ${ }^{3}$ Department of \\ Pharmacology and Toxicology, Faculty \\ of Pharmacy, Al-Rafidain University \\ College, Baghdad, Iraq; ${ }^{4}$ Internal \\ Medicine Department, National \\ Diabetes Center, Al-Mustansiriyah \\ University, Baghdad, Iraq
}

Background and aim: Diabetes self-management behaviors are necessary to ensure optimum glycemic control. However, limited data were available regarding the practice of self-management by the Iraqi diabetic patients. This study aims to understand the knowledge, behaviors, and barriers of diabetes self-management among Iraqi type 2 diabetes mellitus (T2DM) patients in addition to their opinions and views toward the diabetes self-management educational program. Methods: A qualitative method approach was used to obtain the data from T2DM patients recruited from the National Diabetes Center, Baghdad, Iraq. Data were collected using a semistructured interview guide, and a thematic analysis approach was used to process the data.

Results: Most participants agreed to the importance of self-management practices especially healthy eating, exercise, taking medications, and healthy coping with stress to control DM and prevent its complications. Healthy eating and physical activity recommendations were inadequately practiced by most of the participants. Most participants reported irregular self-monitoring of blood glucose. Most of the participants properly adhered to the anti-diabetic medications. They generally lack proper information/knowledge about the importance of self-management practices of foot care and managing diabetes during sick days and how such practices should be implemented. Most participants have positive attitudes toward diabetes self-management practices. Face-to-face educational sessions are preferred by most patients.

Conclusion: The Iraqi diabetic patients have inadequate self-management behaviors. The main barrier to self-management practices was the lack of knowledge due to the absence of diabetes self-management educational programs in Iraq.

Keywords: type 2 diabetes mellitus, Iraq, self-management behaviors, diabetes self-management educational program

\section{Introduction}

Diabetes mellitus (DM) is a chronic metabolic disorder characterized by hyperglycemia that develops as a consequence of insulin deficiency (type $1 \mathrm{DM}$ ) and/or insulin resistance (type $2 \mathrm{DM}$ [T2DM]). It is a common disorder with increasing prevalence worldwide. ${ }^{1,2}$ In Iraq, the prevalence of diabetes had been increased dramatically over the last 4 decades to reach around 20\%. ${ }^{3}$ Moreover, DM is considered as a leading cause of death in most developing countries, ${ }^{4,5}$ especially in Iraq. ${ }^{6}$ This may be attributed to uncontrolled hyperglycemia, which is associated with many serious complications such as renal failure and cardiovascular disorders. ${ }^{2}$

Glycemic control is necessary to reduce morbidity and mortality of DM through the prevention and/or delay of these complications. ${ }^{7}$ Optimum glycemic control can be achieved only when the patients are adherent to self-management behaviors such
Correspondence: Ehab Mudher Mikhael Department of Clinical Pharmacy, College of Pharmacy, University of Baghdad, Al-Shaikh Omar - no. 30, Bab Al Muadham 10047, Baghdad, Iraq Tel +964770 62I 6933 Email ehab_pharma84@yahoo.com

Dovepress if in $>$ 
as healthy diet, physical activity, monitoring of blood glucose, taking medications, reducing the risk factors, ability to resolve diabetes problems, and healthy coping. ${ }^{7-11}$ Therefore, the American Diabetes Association announced that each diabetic patient should participate in diabetes self-management educational (DSME) program. Unfortunately, DSME programs are lacking in Iraq, ${ }^{12}$ and it is impractical to directly adopt a validated DSME program ${ }^{13-15}$ because they were already validated in communities with different health beliefs and cultures from Iraqi patients. ${ }^{16}$ Hence, the development of culturally specific DSME program is mandatory. The first step in developing such a program is to know specifically the self-management behaviors among Iraqi patients. Therefore, the present study aims to understand in depth the DM selfmanagement knowledge, the behaviors, and barriers among Iraqi T2DM patients, in addition to understanding their opinions and views toward the DSME program.

\section{Materials and methods}

\section{Study design}

A qualitative study with face-to-face individual-based semistructured interview was performed with type 2 diabetic patients to get in-depth understanding of the knowledge of Iraqi patients regarding diabetes, its complications, and diabetes self-management, besides exploring patients' selfmanagement behaviors and their views and opinions toward DSME programs.

The questions of the interview guide were open ended, and probes for each question were also used as necessary to elicit further comments. The interview guide was developed by reviewing relevant literatures and validated by a group of experts in the field of diabetes management. ${ }^{17,18}$

\section{Setting and patient recruitment method}

This study was conducted at the National Diabetes Center, Baghdad, Iraq. The National Diabetes Center is the only center in Baghdad that provides diabetic patients with education on insulin self-injection techniques. A follow-up appointment with a clinician, in addition to the low-cost services such as affordability of medications and laboratory tests once every 3-5 months, is commonly provided by this center for every registered diabetic patient. The study protocol was ethically approved by the local research ethics committee of the National Diabetes Center, Baghdad, Iraq. Verbal informed consent was approved by the research ethics committee of the National Diabetes Center; verbal informed consent was obtained from all participants. This study was conducted in accordance with the Declaration of Helsinki.
The study sample includes patients previously diagnosed with T2DM who attended and registered at the National Diabetes Center for routine care and follow-up. The patients were enrolled in this 2-month study in September 2017. The inclusion criteria were adults diagnosed with T2DM for at least 1 year, with a laboratory data confirming their uncontrolled hyperglycemia ( $\mathrm{HbA} 1 \mathrm{c}>7 \%$ ) despite being treated with anti-diabetic medication for at least 3 months.

Patients with impaired physical/mental condition were excluded. As the aim of this study was to describe patients' self-management practices, newly diagnosed patients were not included in this study.

A combination of purposive and convenience strategies was used to enroll the patients in the present study. ${ }^{19}$ The recruitment strategy was based on the patients' age, sex, and educational level. This approach enables the observer to recognize the different forms of self-management practices from different perspectives. The physicians and pharmacists of the diabetes center provide assistance in identifying patients who fulfill the inclusion criteria of the study. We tried to include patients believed to be interactive, open minded, and those who are willing to participate in this study. All patients were informed about the aim of this study, and only patients who provided verbal informed consent were included.

\section{Data collection}

All interviews were conducted by the first author in a diabetes education room within the diabetes center. The interviews were conducted in Arabic, which is the national language of Iraq. All the collected data of the interview were documented using a hard copy method, because most of the participants rejected the audio recording. Each interview consumes approximately 35-70 minutes.

Interviews were conducted until the point of relative saturation with regard to the issues being discussed, the point at which it appeared there was nothing more to be learned.

Initially, all interviews were transcribed verbatim in Arabic and then translated into English for the aim of data presentation. The translated content was coded manually and used for the qualitative data sorting. Codes were given and grouped into categories that were predefined based on the objective of the study. The coding procedure was established by the first author and started by a thorough reading of each interview material.

A thematic content analysis approach was used to categorize the codes thorough several iterations. The thematic areas were patients' knowledge about DM and its complications, 
self-management knowledge, self-management behaviors, and patients' views and opinions toward the DSME program.

\section{Results}

A total of 25 in-depth interviews were conducted with T2DM patients. Twelve of the participants were males and 13 were females. Participants' age ranged from 38 to 73 years. The mean value of disease duration was 8.41 years, and 19 of the participants reported positive family history of T2DM. Five participants were smokers (4 current smokers and 1 was ex-smoker). Regarding the educational status of the participants, 2 of them were $\mathrm{PhD}$ qualified, 7 patients have a BSc degree, 2 have a diploma, and 6 patients were secondary school graduates. In addition, 8 patients have primary and intermediate school qualifications. Nine participants were using insulin alone, 9 were using oral anti-diabetics, and 7 were using insulin plus metformin.

All participants were Arabs. Two of the screened patients deny participation in the study. The themes obtained in this study are listed in Table 1.

\section{DM definition}

Twelve participants defined DM as an elevated blood glucose level. Eleven participants considered diabetes as a serious and fatal disease associated with many dangerous and fatal complications including destruction of all body organs. Three patients recognized diabetes as a chronic disease that need long-term treatment for the rest of their life. Meanwhile, two patients considered diabetes as a psychological disorder and the fluctuation of blood glucose levels are mostly related to uncontrolled mood.

Simply diabetes mellitus is an elevation in blood glucose level. [Female, 50 years old]

Diabetes is similar to cancer because it can destroy all body organs. [Male, 68 years old]

Me and diabetes are friends and we will live together until death. (Male, 60 years old).

Diabetes is a psychological disorder since my blood glucose level is uncontrolled during stress and anxiety. [Female, 59 years old].

\section{Hyperglycemic symptoms and causes}

Four participants did not experience any remarkable symptoms of hyperglycemia, while 21 participants demonstrated the symptoms of hyperglycemia; of them 4 participants suffer from only one symptom, whereas the others suffer from at least 2 symptoms. The most commonly experienced symptoms by the participants were polyuria $(n=12)$, polydipsia $(n=12)$, headache $(n=7)$, weakness $(n=4)$, dizziness $(n=4)$, desire to eat $(n=2)$, and tachycardia $(n=1)$.

I feel dryness in my lips and unusual increase in urination only if my blood glucose exceeds $400 \mathrm{mg} / \mathrm{dL}$. [Male, 64 years old]

I don't have any symptoms for hyperglycemia, I know by chance during laboratory testing. [Male, 65 years old]

Hyperglycemia occurs as a result of non-adherence to a healthy diet ( $\mathrm{n}=21$ participants) such as eating larger meals $(n=10)$, eating sweets $(n=7)$, eating excess of carbohydrates in a meal $(n=7)$, or eating large fatty meals $(n=1)$. Other causes of hyperglycemia among study participants include stress $(n=15)$, non-adherence to timing or dose of medication $(n=3)$, infections $(n=1)$, use of steroids $(n=1)$, and being less active $(n=1)$.

My blood glucose level increased when I eat larger meals and when I go to sleep without any exercise. [Male, 64 years old]

My blood glucose level increased when I eat Pacha (Iraqi fatty meal) and if I eat large amounts of Datli (A type of Iraqi sweets). [Female, 59 years old]

My blood glucose level increased if I'm too late to take my insulin. [Male, 52 years old]

Regarding the management of hyperglycemia, all participants did not seek medical advice even when the hyperglycemia persisted for more than 3 days; instead, most participants $(n=10)$ increased the dose of their medication as a response to the state of hyperglycemia (six participants using insulin and four participants using oral anti-diabetics).

If my blood glucose level exceeds $400 \mathrm{mg} / \mathrm{dl}$ I will take additional 20 units of insulin. [Female, 57 years old]

If my blood glucose increased I take additional dose of my insulin (Mixtard $\AA$ ), I adjust the dose according to my opinion at that moment [Male, 48 years old].

When blood glucose level rises, I take an additional tablet of metformin (Glucophage ${ }^{\circledR}$ ). [Male, 60 years old].

For the treatment of hyperglycemia, 5 participants mentioned that they reduced the size of their meals, 3 participants stopped eating sweets, 2 participants decided to do exercise, two participants just adhered to take their regular medications, 4 participants just increased drinking of water, and 2 participants did nothing. 
Table I Study themes

\begin{tabular}{|c|c|}
\hline Theme & Major and minor category \\
\hline I. General knowledge about diabetes and its complications & $\begin{array}{l}\text { I. What is diabetes? } \\
\text { A. Diabetes definition } \\
\text { 2. Hyperglycemia } \\
\text { A. Symptoms } \\
\text { B. Causes } \\
\text { C. Treatment } \\
\text { 3. Diabetes complications } \\
\text { A. Types } \\
\text { B. Causes } \\
\text { C. Prevention }\end{array}$ \\
\hline 2. Diabetes self-management & $\begin{array}{l}\text { I. Healthy eating } \\
\text { A. Knowledge of types and amounts of healthy foods } \\
\text { B. Practice of healthy eating } \\
\text { 2. Being active } \\
\text { A. Knowledge of types and duration of beneficial exercise } \\
\text { B. Exercise practice } \\
\text { 3. Monitoring of blood glucose } \\
\text { A. Knowledge about frequency and targets for blood glucose testing } \\
\text { B. Practice of blood glucose testing } \\
\text { 4. Medication taking } \\
\text { A. Knowledge about how to take medication } \\
\text { B. Practice of medication adherence } \\
\text { 5. Reducing risks } \\
\text { A. Knowledge about requirements to reduce risks of diabetes complications } \\
\text { B. Practices of daily foot care } \\
\text { 6. Resolving problems } \\
\text { A. Knowledge about managing diabetes during sick days } \\
\text { B. Knowledge about hypoglycemia management } \\
\text { C. Practice managing hypoglycemia } \\
\text { 7. Healthy coping with stress } \\
\text { A. Knowledge about the effect of stress on blood glucose level and methods } \\
\text { B. Practices to cope with stress }\end{array}$ \\
\hline Barriers for DSMP & $\begin{array}{l}\text { I. Patient-related factors } \\
\text { A. Lack of knowledge } \\
\text { B. Lack of awareness } \\
\text { C. Cost } \\
\text { D. Negligence } \\
\text { 2. Environmental factors } \\
\text { A. Hot weather } \\
\text { B. Dangerous situations }\end{array}$ \\
\hline DSME program & $\begin{array}{l}\text { I. Areas that should be covered by program } \\
\text { A. Healthy eating } \\
\text { B. Being active } \\
\text { C. Taking medications } \\
\text { D. Healthy coping } \\
\text { 2. Preferred educational method } \\
\text { A. Direct face to face } \\
\text { B. In-direct (Remote) education } \\
\text { 3. Barriers to join DSME program } \\
\text { A. Patient-related factors } \\
\text { B. Environmental factors }\end{array}$ \\
\hline
\end{tabular}

Abbreviations: DSME, diabetes self-management educational; DSMP, diabetes self-management practices. 
I usually reduce the size of my meal and stop eating sweets for few days, when my blood glucose level is high. [Female, 59 years old].

I don't do anything when I feel hyperglycemic symptoms. [Male, 68 years old].

\section{Diabetes complications}

All participants were able to mention at least 2 diabetic complications. The mentioned complications included heart disease, stroke, visual problems, neuropathy, renal failure, sexual dysfunction (erectile dysfunction), and diabetic foot problems.

Nineteen participants experienced at least one of the diabetic complications, most commonly neuropathy $(n=9)$, sexual dysfunction $(n=4)$, retinopathy $(n=3)$, stroke $(n=3)$, angina $(n=2)$, and diabetic foot $(n=1)$, while 6 participants did not suffer from any DM-related complications.

All participants agreed that uncontrolled hyperglycemia for long periods can predispose to diabetic complications.

Long period of uncontrolled hyperglycemia can cause damage in retina, nerves, and kidneys. [Female, 50 years old]

I used to eat non healthy diet, which don't let me to control my blood glucose level and thus I got stroke, angina and sexual dysfunction. [Male, 64 years old]

Only 2 participants recognized that uncontrolled hypertension along with hyperglycemia can cause macrovascular complications such as angina and stroke.

I think that elevated blood pressure and blood glucose level make me suffer from a heart problem. [Male, 68 years old]

Meanwhile, only one participant mentioned that smoking is a risk factor for cardiovascular disease among diabetic patients.

I have got a heart problem not only because of uncontrolled blood glucose level, but also because I'm a heavy smoker.

[Male, 64 years old]
The most frightening diabetes-related complications for the participants were retinopathy $(n=8)$, nephropathy $(n=7)$, foot amputation $(n=3)$, stroke $(n=2)$, cardiovascular diseases $(n=2)$, sexual dysfunction $(n=1)$, and liver diseases $(n=1)$.

The worst thing according to me is to lose vision. [Female, 50 years old]

Surely renal failure is the worst thing. [Female, 65 years old]

Stroke is the worst complication, look on me, I can't walk steadily and my mouth is skewed. [Male, 62 years old]

\section{Diabetes self-management}

Most of the participants recognized that healthy diet $(n=25)$, physical activity $(n=24)$, regular use of anti-diabetic medications $(n=20)$, monitoring of blood glucose $(n=19)$, regular physician visits $(n=14)$, daily foot care $(n=12)$, and healthy coping with stress $(n=11)$ are essential components of the diabetes self-management practices that can help in controlling blood glucose level and prevent diabetes-related complications (Table 2).

\section{Healthy eating knowledge and practice}

Most of the enrolled participants $(n=24)$ recognized that they should decrease their carbohydrate intake through the reduction of the consumed amount of rice $(n=9)$, fruits $(n=8)$, bread $(n=7)$, and/or avoidance (maximum reduction) of sweets and sugar consumption $(\mathrm{n}=16)$. Moreover, 10 participants mentioned that fat consumption should be reduced through the consumption of white meat instead of red type, in addition to the consumption of grilled or boiled food instead of fried foods. Meanwhile, 7 participants mentioned that they should increase vegetable intake. Two participants thought that acidic foods, such as lemon, are useful to lower their blood glucose level. One participant mentioned that walnut is useful to reduce blood glucose level. In addition, only 1 participant mentioned that he should eat food at consistent time to avoid the fluctuations in blood glucose level. None

Table 2 Attitude and practice of self-management among diabetic patients

\begin{tabular}{|l|l|l|}
\hline Self-management behavior & $\begin{array}{l}\text { Patients with positive attitude toward the } \\
\text { importance of self-management behavior, } \mathbf{n} \\
(\%)\end{array}$ & $\begin{array}{l}\text { Patients who practice the self- } \\
\text { management behavior regularly, } \mathbf{n}(\%)\end{array}$ \\
\hline Healthy eating & $25(100)$ & $5(20)$ \\
\hline Exercise & $24(96)$ & $6(24)$ \\
\hline Taking medications & $20(80)$ & $14(56)$ \\
\hline Self-monitoring of blood glucose level & $19(76)$ & $5(20)$ \\
\hline Regular physician visit & $14(56)$ & $12(48)$ \\
\hline Foot care & $12(48)$ & $4(16)$ \\
\hline Healthy coping with stress & $\mathrm{II}(44)$ & $8(32)$ \\
\hline
\end{tabular}


of the participants mentioned the importance of consuming consistent amount of food (especially carbohydrates). In addition, none of the participants had an idea about the DM meal planning (Table 3).

One should consume moderate amounts of carbohydrate, for example 2 pieces of fruit per day and 6-8 tablespoon of rice in each meal, besides increasing vegetable intake and avoiding red meat and fried foods such fried potato.

[Female, 57 years old]

To ensure best glycemic control, the diabetic patient must chew food well and increase consumption of lemon, since acidic food will lower blood pressure and thus blood glucose level will be lowered. [Male, 65 years old]

One should increase consumption of walnut because it is effective to lower blood glucose level. [Female, 59 years old]

Reduction of starches such as rice, potato and bread, besides avoidance of sweets such as Baklawa (type of Iraqi sweets) and table sugar are necessary for controlling blood glucose level. [Male, 60 years old]

The source of information about healthy diet to the participants was mainly from physician consultation $(n=8)$, Internet sites $(n=5)$, other patients $(n=4)$, citations of medical literatures $(n=3), T V$ programs $(n=2)$, and a consultation from a pharmacist $(n=1)$, whereas two participants mentioned that they collected information from their experience with the disease.

Concerning the adherence to the healthy diet, 5 participants were totally adherent to a healthy food program, whereas 7 participants were adherent for at least 3 days of the week. Thirteen participants were totally non-adherent to healthy eating habits.
I always follow my physician instruction while eating.

[Female, 56 years old]

I eat food that will not affect blood glucose level for 3-4 days/week. [Male, 64 years old]

I'm used to eat sweets and fatty foods all days of the week. [Male, 68 years old]

The reported barriers for non-adherence to the healthy eating include personal sweet preference $(n=8)$, feeling hungry $(n=5)$, eating outside home $(n=5)$, family meal preparation habits and taking meals with the family $(n=4)$, temptation by a friend $(n=3)$, stress of life $(n=3)$, teeth loss $(n=1)$, high cost of the healthy foods $(n=2)$, and lacking of disease symptoms $(n=1)$, and only 1 participant mentioned that there is no barriers for consuming a healthy diet (Table 3).

I can't eat healthy foods when I go to my work since all types of food available in the cafeteria are non-healthy such as chocolates, non-diet juices, fried chicken and potato.

[Male, 48 years old]

I feel hungry all the time, so I can't eat small food portions. [Male, 62 years old]

I can't resist sweets when I see them in front of me. [Female, 59 years old]

Vegetables are useful but I can't eat them since I lost most of my teeth, so I prefer to eat creamy cheese, whole egg, fruits, rice and summon (type of Iraqi soft bread).

[Male, 68 years old]

However, 12 participants agreed with the family role to help them complying with eating a healthy food through preparing special foods, or at least reminding the patient to avoid non-healthy foods. One participant mentioned that

Table 3 Knowledge and barriers to practice health eating behavior

\begin{tabular}{|c|c|c|}
\hline \multicolumn{2}{|l|}{ Parameter } & Patients, n (\%) \\
\hline $\begin{array}{l}\text { Knowledge regarding requirements } \\
\text { for practicing of healthy eating }\end{array}$ & $\begin{array}{l}\text { Reduction of carbohydrate intake } \\
\text { Reduction of fat intake } \\
\text { Increase in vegetable intake } \\
\text { Eating meal at a consistent time } \\
\text { Wrong ideas }\end{array}$ & $\begin{array}{l}24(96) \\
10(40) \\
7(28) \\
I(4) \\
3(12)\end{array}$ \\
\hline Barriers for healthy eating behavior & $\begin{array}{l}\text { Personal preference for sweets } \\
\text { Feeling hungry } \\
\text { Eating outside home } \\
\text { Eating same family meals } \\
\text { Temptation by a friend } \\
\text { Stress of life } \\
\text { Loss of teeth }\end{array}$ & $\begin{array}{l}8(32) \\
5(20) \\
5(20) \\
4(16) \\
3(12) \\
3(12) \\
1(4)\end{array}$ \\
\hline
\end{tabular}

Note: Summation of percentages may be more than $100 \%$ because some patients mentioned more than one parameter and/or barrier for healthy eating. 
the increase in body weight alarms her to adhere to healthy eating patterns.

I usually eat meals similar to what my family eats. However, my blood glucose level is lowered when my wife cooks special meals for me. [Male, 60 years old]

\section{Exercise, knowledge, and practices}

Twenty-four participants know that regular daily walking is useful to control blood glucose level, but only 3 participants mentioned that walking must be brisk to be more useful; meanwhile, only 4 participants mentioned that walking should be at least 30 minutes per day. On the other hand, 4 participants also mentioned that Swedish exercise can be useful for diabetic patients. One participant considered gardening as a useful and sufficient type of physical activity for the diabetic patient, and another one considered cooking and cleaning the house is a sufficient exercise for the diabetic patient (Table 4). None of the participants mentioned other types of aerobic exercises such as cycling, swimming, and tennis, and none mentioned resistant exercise as examples of useful exercise.

Walking to be useful, it must brisk for at least 30 minutes per day. [Male, 48 years old]

I'm always in move inside my house, I cook food by myself, clean the house and sometimes go upstairs, this is a strong exercise that can lower my blood glucose level.

[Female, 40 years old]

The participants of this study mentioned that they get information about the type and duration of exercise mainly from the Internet $(n=4)$, physician $(n=3)$, pharmacist $(n=2)$, other patients $(n=3)$, and/or TV programs $(n=2)$. Meanwhile, eleven participants mentioned that none discussed with them such information. Fifteen participants do exercise through walking; however, only 6 of them walk daily, 6 participants walk 3-4 days/week, and the last 3 participants walk 1-2 times/week. On the other hand, 10 participants denied doing any type of physical activity.

I go (by walking) to pray at the mosque two times daily. [Male, 54 years old]

Although walking is useful but I don't like to go outside home. [Female, 65 years old]

Seven participants said that walking with someone else (a family member or friend) increase their desire to walk daily.

I walk with my friends' everyday. [Male, 60 years old]

The enrolled participants also mentioned many barriers to physical activity (Table 4) including patient-related factors such as suffering from physical pain due to a disc prolapse, osteoarthritis, or neuropathy $(n=9)$; presence of comorbid diseases such as angina and vertigo $(n=3)$, feeling tired $(n=2)$, stress of life $(n=2)$, and busy work schedule $(n=2)$; and environmental factors such as hot weather $(n=4)$, dirty roads $(n=1)$, absence of nearby malls $(n=1)$, and absence of sport centers $(n=1)$.

I can't walk because I have a disc prolapse. My rheumatologist told me to avoid any physical activity. [Male, 73 years old]

I don't like to walk in such dirty road besides absence of any nearby shopping malls. [Female, 65 years old]

I don't walk because I'm afraid it is bad for my heart health since I did open heart surgery. [Male, 64 years old]

\section{Medications taking knowledge and practice}

Only 14 participants know the correct time to take their antidiabetic medication ( 7 were on insulin and 7 using tablets); however, 2 participants (using insulin) do not take their

Table 4 Knowledge and barriers to exercise

\begin{tabular}{|c|c|c|}
\hline Parameter & Patient perspective & Patients, n (\%) \\
\hline Beneficial types of exercises & \begin{tabular}{|l|} 
Walking \\
Swedish exercise \\
Gardening \\
Household chores
\end{tabular} & \begin{tabular}{|l|}
$24(96)$ \\
$4(4)$ \\
$I(4)$ \\
$I(4)$
\end{tabular} \\
\hline Duration of doing exercise & 30 minutes/day & $4(16)$ \\
\hline Barriers for exercising & $\begin{array}{l}\text { Presence of other diseases such as } \\
\text { rheumatoid arthritis, osteoarthritis, angina, } \\
\text { vertigo, and weakness } \\
\text { Stress of life and busy work schedule } \\
\text { Environmental factors such as hot weather, } \\
\text { dirty roads, and lack of sports centers }\end{array}$ & $\begin{array}{l}14(56) \\
4(16) \\
7(28)\end{array}$ \\
\hline
\end{tabular}

Notes: Summation of percentages may be more than 100\% because some participants mentioned more than one type of beneficial exercise. 
medication $1 / 2$ hour before meal because they feel hungry (Table 5).

Most of the participants were educated about the time of using their medications by a physician $(n=15)$, pharmacist $(n=3)$, diabetes educator $(n=2)$, and from other patients $(n=5)$.

My pharmacist told me to inject insulin 1/2 hour before a meal but I usually inject it and eat because I can't wait to eat. [Female, 50 years old]

I usually take metformin (Glucophage $\left.{ }^{\circledR}\right)$ tablets with meals according to physician instructions. [Male, 54 years old]

My sister, a diabetic patient, told me to take glibenclamide (Daonil $\AA$ ) tablets before meals to work properly and I do as she told me. [Male, 63 years old]

I take my insulin injection after meals because if I inject it before meals hypoglycemia may occur. [Male, 65 years old]

All of the 16 participants who use insulin were educated about insulin injection technique, 9 of them by a physician, 2 by a pharmacist, 2 by a diabetes educator, 2 by other patients, and only 1 by a nurse. However, only 14 participants know the need to rotate the injection site of insulin; meanwhile, 2 participants did not rotate the site of injection regularly because they were used to inject at just one site. Most participants prefer to inject insulin in their arms $(n=7)$ or thigh $(n=2)$, while only 5 participants inject insulin using all possible sites (thigh, abdomen, and arm).

I usually inject insulin into my arm, I'm afraid from injecting insulin into other body sites. [Male, 48 years old]

I rotate my insulin injection between arm, thigh and abdomen. [Male, 60 years old]

Fourteen participants ( 9 on insulin and 5 on tablets) are totally adherent to their medication in regard to the dose and time, while other 11 participants did not adhere to their medication through neglecting the medication dose $(n=8 ; 4$ of them on insulin and 4 on tablets), changing (increase or decrease) the medication dose ( $n=3$; all on insulin), and/or changing the time of taking their medication $(n=3)$.

I usually take my medication as prescribed by my physician because I will die if I don't take it. [Female, 56 years old]

I take metformin tablet only if feel hyperglycemic symptoms such as thirst and frequent urination. [Female, 40 years old]

I use a lower insulin dose if my blood glucose level was good, $160 \mathrm{mg} / \mathrm{dl}$. [Male, 64 years old]

When my blood glucose level is less than 100 , I take my insulin injection after a meal. [Male, 52 years old]

The barriers for adherence of the participants to their anti-diabetic medications (Table 5) include forgetfulness ( $\mathrm{n}=7 ; 4$ on insulin and 3 on tablets), absence of hyperglycemic symptoms ( $n=6$; three on both insulin and tablets), high cost of medications $(n=2$; one on both insulin and tablets), fear from hypoglycemia ( $n=2$; all on insulin), being outside home ( $\mathrm{n}=2$ on insulin), pain during injecting insulin $(n=2)$, and increase in body weight ( $n=1$ on insulin), while 3 participants did not mention any barrier to medication adherence.

I don't inject my night dose of insulin because I fear from mid night hypoglycemia. [Female, 50 years old]

I can't take my insulin with me when I go outside my home, since I don't have a refrigerator in my car and I'm afraid that insulin will be damaged when exposed to extreme temperatures during the travel. [Male, 60 years old]

Most of the participants agreed that family members can help to remind them to take medication at the specified time.

My wife usually reminds me to take insulin before meals.

[Male, 73 years old]

Table 5 Knowledge and barriers to take medications regularly

\begin{tabular}{|c|c|c|}
\hline \multicolumn{2}{|l|}{ Parameter } & \multirow{2}{*}{$\begin{array}{l}\text { Patients, n (\%) } \\
12(48) \\
14(87.5)\end{array}$} \\
\hline $\begin{array}{l}\text { Knowledge regarding how to } \\
\text { take anti-diabetic medication }\end{array}$ & $\begin{array}{l}\text { Right time to take anti-diabetic medication (all patients) } \\
\text { Right method of administering insulin (just patients on } \\
\text { insulin therapy) }\end{array}$ & \\
\hline $\begin{array}{l}\text { Main barriers for adherence } \\
\text { to anti-diabetic medications }\end{array}$ & $\begin{array}{l}\text { Forgetfulness } \\
\text { Absence of hyperglycemic symptoms } \\
\text { Cost of medications } \\
\text { Pain of injection } \\
\text { Being outside home } \\
\text { Fear from hypoglycemia } \\
\text { Increase in body weight } \\
\text { No barriers }\end{array}$ & $\begin{array}{l}7(28) \\
6(24) \\
2(8) \\
2(8) \\
2(8) \\
2(8) \\
1(4) \\
3(12)\end{array}$ \\
\hline
\end{tabular}




\section{The knowledge and practice of monitoring blood glucose}

Although most of the participants $(n=23 ; 16$ on insulin and seven on tablets) declared that they have at least one glucometer, but only 22 (16 on insulin and 6 on tablets) of them know how to use the glucometer to monitor their blood glucose levels (Table 6). The participants were educated about the method for testing blood glucose by other patients $(\mathrm{n}=8)$, reading the glucometer manual $(\mathrm{n}=6)$, a pharmacist $(n=5)$, laboratory technician $(n=2)$, or by the physician $(n=2)$.

I read my apparatus manual, it was easy, and then I became expert in testing my blood glucose level. [Male, 48 years old]

When I bought the glucometer from the pharmacy, the pharmacist educates me how to operate it. [Male, 65 years old]

My husband was a diabetic patient he told me how to test blood glucose level by his glucometer. [Female, 56 years old]

Eight participants ( 4 on insulin and 4 on tablets) did not measure their blood glucose levels for more than 6 months. Some of the participants $(\mathrm{n}=12$, ten on insulin and two on tablets) mentioned that they measure their blood glucose levels regularly at least once weekly ( $\mathrm{n}=1$, on tablets), twice weekly ( $\mathrm{n}=1$, on insulin), 3-4 times/week ( $\mathrm{n}=5$, all on insulin), twice daily ( $n=3$, two on insulin and one on tablets), and three times daily ( $\mathrm{n}=2$, all on insulin). On the other hand, 5 participants ( 3 on insulin and 2 on tablets) mentioned that they measure their blood glucose levels irregularly, of whom 4 ( 2 on insulin and 2 on tablets) of them measure their blood glucose levels only when they develop hyperglycemic symptoms and 1 participant (on tablets) usually measure blood glucose level after eating large meals. Fourteen participants declared that they measure their blood glucose levels in the fasting state; only 3 participants measure their blood glucose levels in both fasting and postprandial states, while 1 participant measure blood glucose level in both fasting and pre-prandial states and last participant measure blood glucose level at non-specified times (random blood glucose test; Table 6).

I measure my blood glucose level twice weekly; I usually do one of these measurements before breakfast and the other one 2-3 hours after a meal. [Male, 48 years old]

I test my blood glucose level only if I eat large meals.

[Female, 60 years old]

I test my blood glucose level if I feel dizzy. [Female, 57 years old]

The reported barriers to regular blood glucose testing (Table 6) include the absence of hyperglycemic symptoms $(n=6)$, cost of strips $(n=6)$, unavailability of glucometer $(n=2)$, stress from test results $(n=5)$, pain of the skin puncture $(n=4)$, and negligence $(n=3)$, while two participants mentioned that there are no barriers to testing.

I don't test regularly because in every test I become stressed.

[Female, 62 years old]

Moreover, the enrolled participants recognized that the availability of free or at least low-cost strips $(n=4)$, availability of glucometer without need to puncturing the skin $(n=3)$, and support from a family members $(n=3)$ are helpful in doing regular glucose testing.

If the diabetes center provides us with free testing strips, I will do glucose test daily. [Female, 56 years old]

Table 6 Knowledge and barriers to self-monitoring of blood glucose level

\begin{tabular}{|c|c|c|}
\hline \multicolumn{2}{|l|}{ Parameter } & Patients, n (\%) \\
\hline $\begin{array}{l}\text { Knowledge regarding blood } \\
\text { glucose testing }\end{array}$ & $\begin{array}{l}\text { Operation of glucometer } \\
\text { Doing pre-prandial blood glucose testing } \\
\text { for patients on insulin therapy } \\
\text { Doing at least once daily testing for blood } \\
\text { glucose testing level (for patients on oral } \\
\text { anti-diabetics) }\end{array}$ & $\begin{array}{l}22(88) \\
\text { I (4) } \\
\text { I (4) }\end{array}$ \\
\hline Barrier to glucose testing & $\begin{array}{l}\text { Absence of hyperglycemia symptoms } \\
\text { Cost of strips } \\
\text { Unavailability of glucometer } \\
\text { Stress from test results } \\
\text { Pain of pricking the skin } \\
\text { Negligence }\end{array}$ & $\begin{array}{l}6(24) \\
6(24) \\
2(8) \\
5(20) \\
4(16) \\
3(12)\end{array}$ \\
\hline
\end{tabular}

Note: Summation of percentages may be more than 100\% because some patients mentioned more than one barrier. 


\section{Knowledge and practice about healthy coping with stress}

Twelve participants considered that diabetes is a source of stress for them. Other participants $(n=13)$ denied any stressful effect of diabetes on their life.

Diabetes destroyed my life and make me stressed because I can't eat sweets and perform sexual activities; besides that, diabetes make me fear from death since my father died when he was 50 years old due to renal failure that resulted from his uncontrolled diabetes. [Male, 65 years old]

Twenty-three of the participants realized that stress increases blood glucose level; however, the majority of them $(n=14)$ know that through experiencing hyperglycemic symptoms, while the others ( $\mathrm{n}=9)$ know that through blood glucose testing.

When I'm stressed my blood glucose level may reach $450-480 \mathrm{mg} / \mathrm{dL}$. [Female, 57 years old]

When I'm stressed I know that my blood glucose level is elevated because I go to the toilet every 5 minutes. [Male, 68 years old]

None of the participants was educated about the effect of stress on the blood glucose level and about the methods to cope with stress. Most of the patients cope with stress through social deprivation $(n=9)$, praying $(n=5)$, sleeping $(n=2)$, eating $(\mathrm{n}=2)$, hobbies $(\mathrm{n}=2)$, watching TV $(\mathrm{n}=1)$, going outside home $(n=2)$, smoking $(n=1)$, and doing exercise $(n=1$; Table 7$)$.

During stress, I prefer to eat sweets. [Male, 68 years old]

During stress, I usually scream and go to my room to stay alone there. [Female, 69 years old]

During stress, I prefer to eat sweets. [Male, 68 years old]

All the participants $(n=25)$ considered their lack of knowledge about the importance of doing exercise as a barrier to cope with stress effectively. On the other hand, 5 participants mentioned the weakness during stress as an additional barrier for doing exercise to cope with stress (Table 7).

To relief stress, no one told me what to do. [Male, 64 years old]

Oh, during stress, I feel so tired and just want to go to sleep. [Female, 50 years old]

Moreover, 7 participants considered a major role of family members to lower the burden of stress. Other participants $(n=18)$ mentioned that nothing can help them to relieve stress.

When I become stressed my wife asked me to be calm to avoid getting stroke. [Male, 62 years old]

\section{Knowledge and practice to reduce diabetes risks}

To reduce the risk of diabetes complications, all participants agreed about the importance of controlling blood glucose level; 2 participants considered controlling blood pressure is necessary, and one participant considered quitting smoking is necessary (Table 8). None of the participant mentioned the effect of controlling plasma lipids to reduce diabetes risks.

To reduce negative effects of diabetes on heart one should control not only blood glucose level but also blood pressure.

[Male, 68 years old]

To reduce risk of eye damage, one should keep blood glucose at low levels. [Male, 48 years old]

One should stop smoking and control his blood glucose level to avoid getting angina. [Male, 64 years old]

Regarding regular physician visits, 14 participants thought that a regular physician (endocrinologist) visit is

Table 7 Knowledge and barriers to healthy coping with stress

\begin{tabular}{|c|c|c|}
\hline Parameter & & Patients, n (\%) \\
\hline Methods to cope with stress & $\begin{array}{l}\text { Social deprivation } \\
\text { Praying } \\
\text { Sleeping } \\
\text { Eating } \\
\text { Do hobbies } \\
\text { Watching TV } \\
\text { Going outside home } \\
\text { Smoking } \\
\text { Exercise }\end{array}$ & $\begin{array}{l}9(36) \\
5(20) \\
2(8) \\
2(8) \\
2(8) \\
1(4) \\
2(8) \\
1(4) \\
1(4)\end{array}$ \\
\hline $\begin{array}{l}\text { Barriers to healthy coping with } \\
\text { stress }\end{array}$ & $\begin{array}{l}\text { Lack of knowledge about the method } \\
\text { of healthy coping with stress } \\
\text { Weakness during stress }\end{array}$ & $\begin{array}{l}25(100) \\
5(20)\end{array}$ \\
\hline
\end{tabular}

Note: Summation of percentages may be more than 100\% because some patients mentioned more than one barrier. 
necessary to prevent or at least to detect diabetes complications earlier (Table 8).

Twelve participants visit a physician (endocrinologist or cardiologist) regularly every $3-5$ months; 6 participants do so only when they suffer from health problems and seven participants visit their physician irregularly (at least once a year).

All participants consulted their dentist only if they have toothache. Three participants visited the ophthalmologist once a year, 3 participants visited an ophthalmologist during vision problems, and 19 participants never visited an ophthalmologist during their life.

I visit the national diabetes center every $3-5$ months according to the follow up date given to me by my physician, I check my eyes (retina) with ophthalmologist at least once a year, but I never go to the dentist unless I have a toothache.

[Male, 48 years old]

The reported barriers to regular endocrinologist visits (Table 8) include the costs of physician appointments $(n=10)$, absence of the hyperglycemic symptoms $(n=6)$, negative attitude toward physicians $(n=5)$, busy schedule $(n=4)$, fear from detecting any diabetic complication $(n=2)$, travel abroad $(\mathrm{n}=1)$, physician waiting time $(\mathrm{n}=1)$, and also environmental factors $(n=2)$ such as hot weather and dangerous roads.

I don't visit physician regularly because a high cost for consulting a physician. [Female, 59 years old]

I don't trust physicians so I never go to them for checkups because the knowledgeable Iraqi physicians go outside Iraq. [Male, 68 years old]

Regarding foot care, although all the participants agreed about diabetes as a cause behind the delay in foot wound healing, the increased risk of gangrene, and the possibility of limb amputation, only 3 participants mentioned that they were educated how to do foot care by their physician and 3 participants know that by reading the medical brochures. Meanwhile, only 5 of them had a good knowledge about how to do foot care such as cleaning foot with mild soap solution, drying foot with focus on the area between toes, applying creams to the heels to prevent skin cracking, daily inspecting foot for sores and injuries, avoid walking bare foot, and wearing cotton socks and non-tight shoes.

I usually wash my feet with soap and water once daily and drying them with great focus on area between toes to avoid fungal infections, I inspect my feet to detect any injury as soon as possible, I apply Vaseline ${ }^{\circledR}$ to my heels daily at night, and I usually try to buy and use non tight shoes and cotton socks. [Male, 48 years old]
Moreover, 12 participants considered the daily foot care necessary to prevent diabetic foot problems and amputation, but only 4 participants performed foot care regularly and in an accurate manner.

The barriers to do daily foot care include lack of the required knowledge for daily foot care in the absence of foot injury or skin cracking $(n=15)$, lack of knowledge about the method of foot care $(n=5)$, travel abroad $(n=2)$, negligence $(n=2)$, and backache $(n=1$; Table 8$)$.

I don't know how to prevent foot problems. [Female, 38 years old]

I can't inspect my foot because of my back pain. [Male,

60 years old]

\section{Knowledge and practice about resolving diabetes problems}

The most common problems that are faced by diabetic patients in their life include hypoglycemia and fluctuated blood glucose levels during sick days (Table 9). In this regard, 23 participants suffered from at least one hypoglycemic attack during their life. The reported symptoms of hypoglycemia include tremor $(n=12)$, dizziness $(n=7)$, sweating $(n=6)$, hungry $(n=7)$, blurred vision $(n=1)$, headache $(n=2)$, weakness $(n=6)$, and coma $(n=2)$.

When my blood glucose level is low, I feel sweaty, hungry (even more hungry than when I fast Ramadan), dizzy and unable to stand. [Female, 62 years old]

The main causes of hypoglycemia reported by the participants were not eating or eating less while taking the same dose of their anti-diabetic medications $(n=10)$, delay in the time of the meal $(n=3)$, wrong dose of insulin $(n=3)$, doing exercise $(n=4)$, taking glibenclamide with other medications (insulin or metformin; $n=2)$, eating rocca $(n=1)$, and none know the cause of hypoglycemia.

My blood glucose level will be lowered if I take my glibenclamide (Daonil@) tablet with insulin injection. [Male, 55 years old]

Sometimes I eat smaller dinner meals and inject myself same insulin dose, then I awake up at midnight sweaty and hungry. [Male, 52 years old]

Despite the serious nature of hypoglycemia, 8 participants were not given any information about the management of hypoglycemia. 17 participants have got some information to treat hypoglycemia: 10 of them got this knowledge from other patients, 3 from a physician, 2 from a pharmacist, and 2 from the websites. Meanwhile, only 5 participants managed their 
Table 8 Knowledge and barriers to practices that reduces diabetes risks

\begin{tabular}{|c|c|c|}
\hline \multicolumn{2}{|l|}{ Parameter } & \multirow[b]{2}{*}{$\begin{array}{l}\text { Patients, n (\%) } \\
25(100) \\
2(8) \\
1(20) \\
12(48) \\
3(12) \\
4(16)\end{array}$} \\
\hline $\begin{array}{l}\text { Patient practices to reduce } \\
\text { diabetes risks }\end{array}$ & $\begin{array}{l}\text { Controlling blood glucose level } \\
\text { Controlling blood pressure } \\
\text { Smoking cessation } \\
\text { Regular physician (endocrinologist) visit } \\
\text { Regular ophthalmologist visit } \\
\text { Regular (daily) foot care }\end{array}$ & \\
\hline Barriers to regular physician visit & $\begin{array}{l}\text { Cost of appointment } \\
\text { Lack of symptoms } \\
\text { Negative attitudes toward physicians } \\
\text { Busy schedule } \\
\text { Fear from detecting diabetes } \\
\text { complications } \\
\text { Travel abroad } \\
\text { Physician waiting time } \\
\text { Environmental factors }\end{array}$ & $\begin{array}{l}10(40) \\
6(24) \\
5(20) \\
4(16) \\
2(8) \\
1(4) \\
1(4) \\
2(8)\end{array}$ \\
\hline Barriers to regular foot care & $\begin{array}{l}\text { Lack of knowledge about the importance } \\
\text { of daily foot care in the absence of foot } \\
\text { problems } \\
\text { Lack of knowledge about the method of } \\
\text { doing foot care } \\
\text { Travel abroad } \\
\text { Negligence } \\
\text { Backache }\end{array}$ & $\begin{array}{l}15(60) \\
5(20) \\
2(8) \\
2(8) \\
1(4)\end{array}$ \\
\hline
\end{tabular}

Note: Summation of percentages may be more than 100\% because some patients may mention more than one information.

hypoglycemia by carbohydrate consumption after checking their blood glucose levels, whereas 18 participants consumed carbohydrates without checking their blood glucose levels. Only 2 participants consume $1 / 2$ a cup of fruit juice for treating hypoglycemia, whereas 13 participants consumed large amounts of carbohydrates to manage hypoglycemia, such as a full glass of soft drink with biscuits and baklava; on the other hand, 5 participants consumed one to two small chocolates, 1 participant ate a small piece of fruit, 1 consumed salt and onion, and the last one waited until the time of the next meal, then ate a larger meal to manage hypoglycemia. None of the participant measured blood glucose level after the management of hypoglycemia.

Whenever I feel hungry with tremor in my hand, I go to the refrigerator and eat all sweet that are available inside it without measuring blood glucose level, because I heard from other patients that sweets are necessary to correct low blood glucose level. [Male, 60 years old]

When I feel weakness and sweating, I check my blood glucose level if it is low for example $60 \mathrm{mg} / \mathrm{dL}$ or less, I drink a large can of Pepsi cola and eat some biscuits then I feel strong again, after I feel well I don't test my blood again. [Female, 50 years old]

The most important barriers to self-manage hypoglycemia through the consumption of 15-20 g of glucose (Table 9) include the lack of knowledge about the correct amount of glucose $(n=24)$, fear from hypoglycemia more than hyperglycemia $(n=7)$, fear from hyperglycemia $(n=1)$, and being outside home during the hypoglycemic attack $(n=2)$, while three participants mentioned that there were no barriers.

I don't have any idea about the correct amount of sugars that one should consume to correct low blood glucose level. [Female, 60 years old]

I eat 1 small chocolate only as my physician told me to correct hypoglycemia and not to get elevation in my blood glucose level. [Male, 55 years old]

Although it is well known that many illnesses, especially infections, affect negatively the blood glucose level, but 20 participants mentioned that they do not realize any effect of an illness on their blood glucose level and only 5 participants know that an illness can elevate blood glucose level; 4 participants already have this knowledge because they suffer from severe hyperglycemic symptoms during an illness and 1 participant knows this fact after checking his blood glucose level. All the participants were not educated about the treatment of diabetes during sick days (Table 9), and only 2 participants mentioned that they read about that topic in the Internet pages. Regarding blood glucose testing during sick days, 15 participants mentioned that they do not perform any glucose test, while 8 participants do the test according 
to their usual schedule and only 2 participants increase the number of tests during sick days.

Is there any effect of infections on my blood glucose level?

I don't think so. [Male, 64 years old]

During illness I can't withstand myself, so I don't test

my blood glucose. [Female, 65 years old]

During illness, I usually increase testing of blood glucose level to be on safe side. [Female, 50 years old]

Regarding the use of anti-diabetic medications during sick days, 14 participants were totally adherent to the same dose of their anti-diabetic medication. 9 participants were already non-adherent to their treatment before and during illness, and 1 participant mentioned an intentional dose reduction during an illness.

During illness such as flu, I take a lower dose of insulin because I don't eat as usual since my appetite is low. [Female, 57 years old]

During illness, I continue to take same dose of my medications, even when eat just soups. [Male, 48 years old]

Moreover, 1 participant consults a physician and 3 consult a pharmacist before using any additional treatment during an illness, since they fear from drug-drug interaction and from the effect of some medications on their blood glucose level.

Before I purchase any medication from a pharmacy I told the pharmacist I have diabetes and asked him not to give me syrups for treatment since they are sweet. [Male, 55 years old]

\section{Perspectives toward DSME program}

Most of the participants $(n=18)$ have positive attitude, 2 participants have negative attitude, and 5 had neutral (thought it can benefit only newly diagnosed diabetic patients) attitude toward DSME programs (Table 10).

I think that any educational program about diabetes will improve my knowledge and help me in controlling diabetes.

[Male, 48 years old]

I tried to attend many educational lectures but I can't get benefit from any. [Male, 73 years old]

Surely educational programs can improve the knowledge of diabetic patients especially those who are newly diagnosed. Meanwhile such programs are not beneficial for patients with a long history of diabetes (like me) because they already have a good knowledge about diabetes.

[Female, 59 years old]

Regarding the educational needs of the participants, the majority $(n=14)$ of participants mentioned that they are in need for more information about healthy eating (ie, the amount of food that the diabetic patient must eat in each meal, foods that do not affect on the blood glucose level, and foods with possible glucose-lowering effects), insulin therapy ( $n=7$; ie, insulin injecting technique, storage of insulin, and calculation of correcting insulin dose), exercise ( $n=4$; ie, the type and duration of beneficial exercises and the methods to reduce the risk of exercise-induced hypoglycemia), blood glucose monitoring $(n=3$; ie, testing glucometer accuracy and the targets of blood glucose level), coping with stress $(n=3)$, and management of diabetes during sick days $(n=1$; Table 10).

If an educational program established I will join it if it will discuss information about food intake and how much one should eat in each meal. [Male, 64 years old]

I wish there is a DSME program that focus on educating us how to inject insulin with less pain. [Female, 65 years old]

Ten participants preferred face-to-face educational sessions. Seven participants preferred reading brochures to get

Table 9 Knowledge and barriers to detect and resolve diabetes problems

\begin{tabular}{|c|c|c|}
\hline Parameter & & $\begin{array}{l}\text { Patients, } \mathbf{n} \\
\text { (\%) }\end{array}$ \\
\hline $\begin{array}{l}\text { Main problems faced by } \\
\text { diabetic patients }\end{array}$ & $\begin{array}{l}\text { Hypoglycemia } \\
\text { Inability to control blood glucose level during } \\
\text { sick days }\end{array}$ & $\begin{array}{l}23(92) \\
5(20)\end{array}$ \\
\hline $\begin{array}{l}\text { Barriers to manage } \\
\text { hypoglycemia in a correct } \\
\text { way }\end{array}$ & $\begin{array}{l}\text { Lack of knowledge } \\
\text { Fear from hypoglycemia } \\
\text { Fear from developing hyperglycemia } \\
\text { Being outside home during hypoglycemia attack }\end{array}$ & $\begin{array}{l}24(96) \\
7(28) \\
1(4) \\
2(8)\end{array}$ \\
\hline $\begin{array}{l}\text { Barriers to manage diabetes } \\
\text { during sick days }\end{array}$ & $\begin{array}{l}\text { Lack of sufficient knowledge (what to do to } \\
\text { manage diabetes during sick days) }\end{array}$ & $23(92)$ \\
\hline
\end{tabular}

Note: Summation of percentages may be more than $100 \%$. 
the required information, while 6 preferred the Internet to get the information and only 2 participants preferred to get the information through watching TV programs (Table 10).

If you make an educational site on Facebook to educate us it will be great. [Male, 65 years old]

It is best for me to discuss information with a pharmacist or physician as we discuss now to learn about permissible amount of food in each meal. [Male, 64 years old]

The reported barriers to join the educational program (Table 10) include patient-related factors such as busy schedule $(n=4)$, lack of health $(n=2)$, cost of transportation $(n=2)$, lack of trust in its benefit $(n=2)$, and environmental factors such as the traffic $(n=4)$, dangerous situations $(n=2)$, and hot weather $(n=3)$. However, six participants mentioned that there were no barriers for joining the DSME program.

I can't join a program if this means additional visits to diabetes center other than my follow up visits because you know hot weather and dangerous situation in Baghdad.

[Female, 50 years old]

\section{Discussion}

In this study, most of the participants were able to define diabetes correctly as a chronic serious disease associated with an elevation in blood glucose level, while few of them defined diabetes as a psychological disorder. Similar finding was reported by a study conducted in Iran, in which most patients define diabetes as a serious disease that can damage the body organs, while others link diabetes to emotional conflicts. ${ }^{20}$ Although hyperglycemic symptoms are diverse, most of the participants in this study mentioned polyuria and polydipsia as major symptoms of hyperglycemia; a similar finding was reported by another study conducted in Scotland. ${ }^{21}$ The most striking finding in this regard was the inability of some participants to mention (did not know) any hyperglycemic symptoms as they experienced no symptoms of hyperglycemia despite their uncontrolled blood glucose levels; this could be explained in that those participants may have silent hyperglycemia because of their long history of uncontrolled blood glucose, ${ }^{22}$ and on the other hand, they did not receive any education about diabetes and its symptoms.

In this study, most participants declared that the lack of adherence to healthy eating patterns can result in hyperglycemia, which is in tune with a similar finding reported by Brod et al when studying the main cause of postprandial hyperglycemia. ${ }^{23}$ On the other hand, a large proportion of participants linked hyperglycemia with stress due to stressful life represented by lack of clean water and electricity besides the political instability in Iraq.

Most of the participants mentioned that they usually increase the dose of their anti-diabetic medication at their next meal when hyperglycemia occurs. Although the use of correcting insulin dose is a common practice among diabetic patients all over the world, ${ }^{23}$ the difference to the current scenario is that Iraqi patients performed this practice without any previous knowledge about the method of calculating the correcting insulin dose. Therefore, all diabetic patients on insulin therapy should be educated about the calculation of correcting insulin doses. On the other hand, some of the participants preferred to

Table 10 Diabetic patients' perspectives toward DSME program

\begin{tabular}{|c|c|c|}
\hline \multicolumn{2}{|l|}{ Parameter } & \multirow{2}{*}{$\begin{array}{l}\text { Patients, n (\%) } \\
18(72) \\
5(20) \\
2(8)\end{array}$} \\
\hline Attitudes of patients toward DSME program & $\begin{array}{l}\text { Positive attitude } \\
\text { Neutral attitude } \\
\text { Negative attitude }\end{array}$ & \\
\hline The participants' educational needs & $\begin{array}{l}\text { Healthy eating (amount of food and healthy food types) } \\
\text { Medications (correct use and storage of anti-diabetics) } \\
\text { Exercise (types and duration) } \\
\text { Methods of monitoring of blood glucose level } \\
\text { Methods of healthy coping with stress } \\
\text { Management of diabetes during sick days }\end{array}$ & $\begin{array}{l}14(56) \\
7(28) \\
4(16) \\
3(12) \\
3(12) \\
1(4)\end{array}$ \\
\hline $\begin{array}{l}\text { Method for administrating DSME according to } \\
\text { the participants' preference }\end{array}$ & $\begin{array}{l}\text { Direct face-to-face educational sessions } \\
\text { Reading medical brochures } \\
\text { Specific websites or Facebook } \\
\text { TV programs }\end{array}$ & $\begin{array}{l}10(40) \\
7(28) \\
6(24) \\
2(8)\end{array}$ \\
\hline Barriers to join DSME program & $\begin{array}{l}\text { Busy schedule } \\
\text { Lack of health } \\
\text { Cost } \\
\text { Lack of trust in its benefit } \\
\text { Environmental factors }\end{array}$ & $\begin{array}{l}4(16) \\
2(8) \\
2(8) \\
2(8) \\
9(36)\end{array}$ \\
\hline
\end{tabular}

Note: Summation of percentages may be less or more than 100\% depending on participants' answers.

Abbreviation: DSME, diabetes self-management educational. 
eat less/more carefully at their next meal when hyperglycemia occurs, although this practice seems to be more safe than arbitrary increase in the anti-diabetic medication dose, but usually participants do so for a short period of time and then return back to their old eating habits; therefore, reinforcement to such practices is necessary to prevent relapsing.

In this study, most of the participants (36\%) suffer from diabetes complications especially neuropathy, while neuropathy was present among $13 \%$ of Indian patients, ${ }^{24}$ however, this difference may be attributed to that the Indian study involved only newly diagnosed diabetic patients in contrast to the current study, which only involved patients with a relatively long history of diabetes.

Most of the participants considered blindness and renal failure as the most frightening diabetes complications, and few of them consider macrovascular complications such as stroke or heart attack as the most dangerous complications, which agreed with that reported in many other studies. ${ }^{25,26}$

All the participants of the present study declared that only uncontrolled hyperglycemia is a risk factor for diabetes complications, but only few of them had an idea that smoking, uncontrolled hypertension, and dyslipidemia are additional risk factors, especially for diabetes macrovascular complications, ${ }^{27}$ this may be attributed to most of the participants who had no history of macrovascular complications, in tune with another study that found a poor knowledge about the cause and risk factors of foot ulcers among diabetic patients with no history of this complication. ${ }^{28}$

This present study showed that the participants have at least some awareness toward the importance of self-management behaviors to control diabetes and prevent its complications, where all participants considered healthy diet as the most important aspect of the self-management behaviors during management of diabetes, because the effect of excessive eating is directly prominent on blood glucose level. Similar result was obtained among Ethiopian patients who also considered diet as an essential part of diabetes self-management. ${ }^{18}$

The present study found that most participants rarely practiced the required daily diabetes self-management protocols; this may be due to their limited knowledge about diabetes self-management practices, ${ }^{29}$ which may be attributed to the unavailability of educational programs for Iraqi diabetic patients, ${ }^{12}$ and thus, most participants received their education about diabetes self-management from other patients or Internet sites. Similarly, a diabetes self-management knowledge gap was also common among Nigerian diabetic patients. ${ }^{30}$

This current study showed that adherence to medication was the most commonly practiced diabetes self-management.
A similar finding was reported among Ethiopian patients, which indicated that they are complying with medication adherence more than any of the other parts of the selfmanagement practices. ${ }^{18}$ This could be due to the fact that medication adherence is easier than adherence to other components of self-management, besides the availability of most anti-diabetic medications for free to Iraqi patients in public hospitals and health care centers. ${ }^{31}$

This study also showed that the main barrier to healthy eating habits was the personal food craving and preference; this craving may result from the need of diabetic patients to change the amount and type of food they eaten. ${ }^{32}$ Additional barrier is related to the Iraqi culture that does not encourage men to participate in food preparation or even to be seen in the kitchen. That means a man with diabetes has to eat anything served to the family. The high cost of healthy food items available for diabetic patients and craving for cultural/ traditional food (Fatty food) are among the other barriers to dietary self-management practices, and similar findings were reported by other researchers in Ethiopia and Sub-Saharan Africa. ${ }^{18,33}$

The main barrier for doing physical activity includes both personal (busy schedule and physical pain) and environmental factors (hot weather, dirty roads, and absence of malls), and this may be attributed to the lack of information about the types and duration of beneficial exercises other than walking, ${ }^{18}$ such as spinning bikes and resistant exercise that are more suitable as an indoor activity during hot or rainy weather, ${ }^{34,35}$ in addition to swimming which is more suitable for patients with rheumatologic pain. ${ }^{36}$ Although the barriers for adherence to the anti-diabetic medication are mostly patient related such as forgetfulness, ${ }^{37}$ the lack of hyperglycemic symptoms, medication side effects, ${ }^{18,38}$ and the cost of medication were also considered. Similar findings were reported in many other studies conducted in both developed and developing countries..$^{37,38}$

On the other hand, the patient-related factors such as absence of hyperglycemic symptoms, stress from test results, pain of the skin puncture, cost of testing, and negligence were also implicated as barriers to regular blood glucose monitoring. Similar barriers were mentioned among Asian diabetic patients who live in Canada. Meanwhile, the practice of glucose monitoring was better among Asian patients compared to Iraqi patients, this may be attributed to the fact that only few Iraqi patients, compared to most Canadian patients, were educated about glucose monitoring by a health care professional. ${ }^{39}$

In the present study, the barriers for regular physician consultation were mainly patient related such as lack of 
awareness, cost of appointments, and time constraints; similar findings were found in a study conducted among American patients. ${ }^{40}$ Additional barrier includes negative attitude toward physicians, which is quite unique for Iraqi participants; this may be attributed to the thought that most of the knowledgeable physicians were immigrated outside Iraq.

Moreover, the barriers to daily foot care, coping with stress, self-managing hypoglycemia, and management of diabetes during sick days were mainly attributed to the lack of sufficient knowledge, which showed that only few participants were educated about the seriousness of diabetes complications, ${ }^{18,28,42}$ and the importance of doing such selfmanagement practices to reduce the risk of these complications. Similarly, the main barrier to diabetes self-management among Ethiopian ${ }^{18}$ and African American diabetic patients was the lack of sufficient knowledge. ${ }^{41}$

This study found that the majority of participants have positive attitude toward DSME programs; a similar finding was reported in other studies conducted in Malawi ${ }^{43}$ and Brazil. ${ }^{44}$ In addition, most of the participants in this study mentioned that they prefer face-to-face educational sessions, which is in tune with the finding reported by Fan and Sidani; this may be attributed to that face-to-face session, which is the only way to encompass empathic discussions with patients. ${ }^{45}$ Meanwhile, most participants of this study preferred (in need) to receive education about healthy eating habits, especially the amount and type of healthy foods; this educational need may be based on the fact that healthy eating is the most challenging part of diabetes self-management, since it should be done on daily basis and represents the greatest impact on patient's lifestyle. Similarly, the educational needs for Malawian diabetic patients were mainly related to food intake. ${ }^{43}$

The present study also showed that the barriers to join an educational program are diverse and include patient-related factors such as busy schedule, having comorbid diseases, cost of transportation, and lack of trust in its benefit; similar finding was reported in many other studies. ${ }^{46,47}$ The other barriers for joining DSME program were unique for Iraqi patients and include extremely hot weather and the dangerous sectorial violence in Iraq; thus, DSME programs can be accomplished through few comprehensive sessions, while patients visiting health care centers for doing routine checkups.

The major limitations of this study were including a sample from only one diabetes center in Baghdad, besides the small sample size; therefore, a larger study sample from different diabetes centers at different Iraqi governorates is needed to confirm the results of the present study.

\section{Conclusion}

Iraqis with T2DM possess poor knowledge and practices of diabetes self-management. Their belief in the importance of diabetes self-management practices represents a motivator for their positive attitude toward participation in face-to-face educational sessions.

\section{Acknowledgments}

The authors thank the staff of the Iraqi Diabetes Center for the technical support.

\section{Disclosure}

The authors report no conflicts of interest in this work.

\section{References}

1. Ogurtsova K, da Rocha Fernandes JD, Huang Y, et al. IDF Diabetes Atlas: Global estimates for the prevalence of diabetes for 2015 and 2040. Diabetes Res Clin Pract. 2017;128:40-50.

2. Chawla A, Chawla R, Jaggi S. Microvasular and macrovascular complications in diabetes mellitus: Distinct or continuum? Indian J Endocrinol Metab. 2016;20(4):546-551.

3. Mansour AA, Al Douri F. Diabetes in Iraq: facing the epidemic. A systematic review. Wulfenia. 2015;22(3):258-278.

4. Islam SM, Purnat TD, Phuong NT, Mwingira U, Schacht K, Fröschl G. Non-communicable diseases (NCDs) in developing countries: a symposium report. Global Health. 2014;10:81.

5. Anonymous. The mysteries of type 2 diabetes in developing countries. Bull World Health Organ. 2016;94(4):241-242.

6. The Institute for Health Metrics and Evaluation. Leading Cause of Death in Iraq. Available from: http://www.healthdata.org/iraq. Accessed June, 2018.

7. American Diabetes Association. 1. Improving care and promoting health in populations: standards of medical care in diabetes-2018. Diabetes Care. 2018;41(Suppl 1):S7-S12.

8. Shrivastava SR, Shrivastava PS, Ramasamy J. Role of self-care in management of diabetes mellitus. J Diabetes Metab Disord. 2013;12(1):14.

9. Collins MM, Bradley CP, O'Sullivan T, Perry IJ. Self-care coping strategies in people with diabetes: a qualitative exploratory study. $B M C$ Endocr Disord. 2009;9:6.

10. Zheng YP, Wu LF, Su ZF, Zhou QH. Development of a diabetes education program based on modified AADE diabetes education curriculum. Int J Clin Exp Med. 2014;7(3):758-763.

11. Tomky D, Cypress M, Dang D. AADE position statement: AADE 7 self-care behaviors. Diabetes Educ. 2008;34:445-449.

12. Ministry of Health. Health in Iraq: The Current Situation, Our Vision for the Future and Areas of Work. 2nd ed. December 2004. Available from: http://www.who.int/hac/crises/irq/background/Iraq_Health_in_ Iraq_second_edition.pdf. Accessed November, 2017.

13. Krebs JD, Parry-Strong A, Gamble E, et al. A structured, group-based diabetes self-management education (DSME) programme for people, families and whanau with type 2 diabetes (T2DM) in New Zealand: an observational study. Prim Care Diabetes. 2013;7(2):151-158.

14. Gamboa Moreno E, Sánchez Perez Á, Vrotsou K, et al. Impact of a selfcare education programme on patients with type 2 diabetes in primary care in the Basque Country. BMC Public Health. 2013;13:521.

15. Tavakol Moghadam S, Najafi SS, Yektatalab S. The effect of self-care education on emotional intelligence and hbalc level in patients with type 2 diabetes mellitus: a randomized controlled clinical trial. Int $J$ Community Based Nurs Midwifery. 2018;6(1):39-46.

16. Beck J, Greenwood DA, Blanton L, et al. 2017 National Standards for Diabetes Self-Management Education and Support. Diabetes Educ. 2017;43(5):449-464. 
17. Laranjo L, Neves AL, Costa A, Ribeiro RT, Couto L, Sá AB. Facilitators, barriers and expectations in the self-management of type 2 diabetes - a qualitative study from Portugal. Eur J Gen Pract. 2015;21(2):103-110.

18. Tewahido D, Berhane Y. Self-care practices among diabetes patients in addis ababa: a qualitative study. PLoS One. 2017;12(1):e0169062.

19. Alzubaidi H, Mc Namara K, Browning C, Marriott J. Barriers and enablers to healthcare access and use among Arabic-speaking and Caucasian English-speaking patients with type 2 diabetes mellitus: a qualitative comparative study. BMJ Open. 2015;5(11):e008687.

20. Abolghasemi R, Sedaghat M. The patient's attitude toward type 2 diabetes mellitus, a qualitative study. J Relig Health. 2015;54(4): 1191-1205.

21. Parry O, Peel E, Douglas M, Lawton J. Patients in waiting: a qualitative study of type 2 diabetes patients' perceptions of diagnosis. Fam Pract. 2004;21(2):131-136.

22. Frankum S, Ogden J. Estimation of blood glucose levels by people with diabetes: a cross-sectional study. Br J Gen Pract. 2005;55(521):944-948.

23. Brod M, Nikolajsen A, Weatherall J, Pfeiffer KM. Understanding postprandial hyperglycemia in patients with type 1 and type 2 diabetes: a web-based survey in Germany, the UK, and USA. Diabetes Ther. 2016;7(2):335-348.

24. Sosale A, Prasanna Kumar KM, Sadikot SM, et al. Chronic complications in newly diagnosed patients with Type 2 diabetes mellitus in India. Indian J Endocrinol Metab. 2014;18(3):355-360.

25. Papaspurou M, Laschou VC, Partsiopoulou P, et al. Fears and health needs of patients with diabetes: a qualitative research in rural population. Med Arch. 2015;69(3):190-195.

26. Cohen MZ, Tripp-Reimer T, Smith C, Sorofman B, Lively S. Explanatory models of diabetes: patient practitioner variation. Soc Sci Med. 1994;38(1):59-66.

27. Silva EFF, Ferreira CMM, Pinho L. Risk factors and complications in type 2 diabetes outpatients. Rev Assoc Med Bras. 2017;63(7):621-627.

28. Gale L, Vedhara K, Searle A, Kemple T, Campbell R. Patients' perspectives on foot complications in type 2 diabetes: a qualitative study. $\mathrm{Br} J$ Gen Pract. 2008;58(553):555-563.

29. Kugbey N, Oppong Asante K, Adulai K. Illness perception, diabetes knowledge and self-care practices among type-2 diabetes patients: a cross-sectional study. BMC Res Notes. 2017;10(1):381.

30. Adisa R, Fakeye TO, Okorie LK. Knowledge, attitude and self-management practices of patients with type 2 diabetes in an ambulatory care setting in Ibadan, Nigeria. Ethiopian Pharm J. 2010;28(2):143-153.

31. Al-Maskari F, El-Sadig M, Al-Kaabi JM, Afandi B, Nagelkerke N, Yeatts KB. Knowledge, attitude and practices of diabetic patients in the United Arab Emirates. PLoS One. 2013;8(1):e52857.

32. Carolan M, Holman J, Ferrari M. Experiences of diabetes self-management: a focus group study among Australians with type 2 diabetes. $J$ Clin Nurs. 2015;24(7-8):1011-1023.
33. Lekoubou A, Awah P, Fezeu L, Sobngwi E, Kengne AP. Hypertension, diabetes mellitus and task shifting in their management in sub-Saharan Africa. Int J Environ Res Public Health. 2010;7(2):353-363.

34. Diabetes Canada Clinical Practice Guidelines Expert Committee. Diabetes Canada 2018 Clinical Practice Guidelines for the Prevention and Management of Diabetes in Canada. Can J Diabetes. 2018;42(Suppl 1):S88-S103.

35. Jenkins DW, Jenks A. Exercise and diabetes: a narrative review. J Foot Ankle Surg. 2017;56(5):968-974.

36. Thent ZC, das S, Henry LJ. Role of exercise in the management of diabetes mellitus: the global scenario. PLoS One. 2013;8(11):e80436.

37. Peeters B, van Tongelen I, Duran Z, et al. Understanding medication adherence among patients of Turkish descent with type 2 diabetes: a qualitative study. Ethn Health. 2015;20(1):87-105.

38. Habte BM, Kebede T, Fenta TG, Boon H. Barriers and facilitators to adherence to anti-diabetic medications: Ethiopian patients' perspectives. Afr J Prim Health Care Fam Med. 2017;9(1):e1-e9.

39. Gucciardi E, Fortugno M, Senchuk A, Beanlands H, Mccay E, Peel EE. Self-monitoring of blood glucose in Black Caribbean and South Asian Canadians with non-insulin treated Type 2 diabetes mellitus: a qualitative study of patients' perspectives. BMC Endocr Disord. $2013 ; 13: 46$

40. Taber JM, Leyva B, Persoskie A. Why do people avoid medical care? A qualitative study using national data. J Gen Intern Med. 2015;30(3):290-297.

41. Onwudiwe NC, Mullins CD, Winston RA, et al. Barriers to self-management of diabetes: a qualitative study among low-income minority diabetics. Ethn Dis. 2011;21(1):27-32.

42. Lawton J, Rankin D, Cooke DD, et al. Self-treating hypoglycaemia: a longitudinal qualitative investigation of the experiences and views of people with Type 1 diabetes. Diabet Med. 2013;30(2):209-215.

43. Ogunrinu T, Gamboa-Maldonado T, Ngewa RN, Saunders J, Crounse J, Misiri J. A qualitative study of health education experiences and self-management practices among patients with type 2 diabetes at Malamulo Adventist Hospital in Thyolo District, Malawi. Malawi Med J. 2017;29(2):118-123.

44. Vieira Gdelc, Cecílio SG, Torres Hdec. The perception of users with diabetes regarding a group education strategy for the promotion of self-care. Escola Anna Nery - Revista de Enfermagem. 2017;21(1):e20170017.

45. Fan L, Sidani S. Preferences for diabetes self-management education interventions: an exploration. Can J Diabetes. 2016;40(5):S30-S74.

46. Graziani C, Rosenthal MP, Diamond JJ. Diabetes education program use and patient-perceived barriers to attendance. Fam Med. 1999;31(5):358-363.

47. Cauch-Dudek K, Victor JC, Sigmond M, Shah BR. Disparities in attendance at diabetes self-management education programs after diagnosis in Ontario, Canada: a cohort study. BMC Public Health. 2013;13:85.

Diabetes, Metabolic Syndrome and Obesity: Targets and Therapy

\section{Publish your work in this journal}

Diabetes, Metabolic Syndrome and Obesity: Targets and Therapy is an international, peer-reviewed open-access journal committed to the rapid publication of the latest laboratory and clinical findings in the fields of diabetes, metabolic syndrome and obesity research. Original research, review, case reports, hypothesis formation, expert opinion and commentaries are all considered for publication. The manuscript management system is completely online and includes a very quick and fair peer-review system, which is all easy to use. Visit http://www.dovepress.com/testimonials.php to read real quotes from published authors. 